\title{
Althusser sobre Lévi-Strauss e sobre o Estatuto da Antropologia Cultural
}

Marco Vanzulli

Universidade de Milão

Em 1965, quando o estruturalismo de Lévi-Strauss já tinha transcendido as fronteiras da etnologia, Edmund Leach publica, no número 34 da New Left Review, um texto intitulado "Claude Lévi-Strauss, Anthropologist and Philosopher". Nele, Leach busca refletir, um pouco a contragosto e com bastante ironia, sobre a relação do estruturalismo com o grande público e sobre a própria figura de Lévi-Strauss como "filósofo" e indiscutível celebridade do panorama intelectual francês: "Já começouse a citá-lo como o filósofo fundador do estruturalismo", diz, "assim como se fala de Sartre como fundador do existencialismo". Leach aceita de bom grado a idéia de julgar a competência de Lévi-Strauss quando este analisa o material etnográfico, mas quando se trata de analisar sua reputação como filósofo confessa um certo incômodo e distanciamento.

O objetivo do dossiê que se segue é o de, precisamente, trilhar um caminho inverso - da filosofia à antropologia. Parte-se, assim, de uma reflexão contemporânea, realizada pelo filósofo italiano Marco Vanzulli, sobre um debate menos conhecido mas nem por isso menos efusivo - que o affaire Sartre / Lévi-Strauss: a crítica de Louis Althusser à "ideologia etnológica" de Claude Lévi-Strauss. Trata-se de um comentário publicado originalmente em italiano e divulgado, agora, pela CAMPOS.

Muitas das diatribes que o debate marxismo / estruturalismo tem produzido são, já, amplamente conhecidas. No caso da presente publicação, a vantagem consiste em poder retomar a discussão em um contexto menos acalorado e sem o risco de que o debate seja arbitrariamente catalogado sob algum tipo de "moda" (seja ela estruturalista ou pós-estruturalista). Por último, e como anexo, disponibilizamos ao leitor a tradução da própria crítica de Althusser. Uma crítica que ele mesmo qualifica como "unilateral" mas que, acrescentemos nós, constitui um pretexto para constatar, uma vez mais, que Lévi-Strauss continua sendo "bom para pensar".

Lorenzo Macagno 
Marco Vanzulli

As poucas páginas do texto althusseriano sobre Lévi-Strauss ${ }^{1}$ pressupõem uma crítica completa de todos os motivos teóricos fundamentais do pensamento do antropólogo estruturalista. $\mathrm{O}$ discurso crítico nos confrontos com Lévi-Strauss está centrado na distinção entre ciência e ideologia. Esse breve artigo é certamente apenas um plano de trabalho, contudo os temas da crítica não são improvisados, mas já estão presentes, ligados solidamente entre si, como o resultado de uma reflexão que está longe de ser extemporânea. Já em Sur Feuerbach², Althusser observava que quando Lévi-Strauss mostra que as estruturas da linguagem, da troca de bens, das mulheres e das palavras repetem a estrutura dos mitos, não se compreende o que repete o que. Assumindo a repetição como uma estrutura do ideológico, esse isomorfismo revela esconder, por sua vez, uma ideologia da relação dos níveis da realidade social, isto é, em última análise, a negação da diferença entre eles. Freud de fato ensinou que a repetição é sempre, e apenas, o sintoma de outra coisa qualquer que se realiza nela através do desconhecimento do que foi removido e aflora no sintoma. ${ }^{3}$ Lévi-Strauss, então, reproduz o reflexo, a reduplicação que é própria do ideológico, e, como Feuerbach, não o consegue. Na sua obra, falta de fato completamente uma teoria das diferentes instâncias da complexidade social. Ainda em Sur Feuerbach, Althusser revelava como também o uso do conceito de inconsciente feito por Lévi-Strauss indicava a natureza ideológica do seu pensamento, e se perguntava por quais razões seria preciso chamar de inconsciente o conhecimento objetivo de uma sociedade, em oposição à consciência que ela tem de si mesma. Existe talvez um inconsciente físico ou químico? Na verdade, Lévi-Strauss rebateria que o conhecimento do ideológico é imanente à ideologia. E assim afirmaria a tese fundamental de toda a hermenêutica. Só por via desse pertencimento do conhecimento ao ideológico, Lévi-Strauss pode evitar a questão principal, aquela da natureza diferencial do próprio objeto. A hermenêutica não assume o ensinamento freudiano mais importante, segundo o qual o inconsciente é outro em relação aos efeitos de sentido da consciência, e o seu discurso é um outro discurso. A razão do sintoma é procurada fora do próprio sintoma. Em Pour Marx, Althusser escreveu que "o sentido disso tudo, de uma simples ideologia [...] depende não de suas relações com uma verdade diferente dela, mas de suas relações com o campo ideológico existente, com os problemas e com a estrutura social que o sustentam e que se refletem mutuamente", e isso implica que "o princípio motor do desenvolvimento de uma ideologia particular não reside portanto dentro da própria ideologia, mas sim fora, aquém da ideologia particular". ${ }^{4}$

Em Sur Lévi-Strauss, essa crítica é retomada exatamente nesse ponto e, sobre este ponto, é definida com maior precisão. $\mathrm{O}$ isomorfismo em Lévi-Strauss depende do fato de que "Lévi-Strauss não sabe de fato o que seja um modo de produção". Althusser critica o antropólogo estruturalista por declarar-se marxista e por remeter-se à teoria de Marx sem nem conhecê-la nem saber aplicá-la. O que o demonstra é o fato de que Lévi-Strauss compartilha da ideologia etnológica que considera as sociedades "primitivas" como sociedades particulares, diferentes de todas as outras, o que impede de empregar a elas as categorias marxistas válidas para as outras sociedades. Se trataria ainda, segundo Althusser, do velho mito rousseauniano da plenitude e verdade originárias, unido neste caso à "má consciência" dos etnólogos, filhos do colonialismo. E, no entanto, Lévi-Strauss pretende dar vida a uma teoria das ideologias. Como é possível, pergunta-se Althusser, se ele não entende qual é a importância, para uma teoria marxista, do conceito de modo de produção? Se não entende portanto que as estruturas de parentesco não subjazem ao formalismo de uma lógica combinatória universal, mas dependem das relações de produção, com as 
quais, nas sociedades ditas primitivas, se confundiam? Com a descoberta do "continente-História", Marx ofereceu um novo fundamento a todas as ciências sociais e humanas: "Marx, com as suas descobertas, nos forneceu pela primeira vez os conceitos científicos capazes de nos fazer compreender o que são as 'sociedades humanas' e sua história, isto é, a sua estrutura, a sua subsistência, o seu desenvolvimento, a sua estagnação, a sua degeneração - e as transformações que ali ocorrem [...] uma formação social designa toda 'sociedade concreta' historicamente existente, e que é individualizada, portanto distinta das suas contemporâneas e de seu próprio passado, pelo modo de produção que ali predomina"s.

O mito rousseauniano da origem implica a consideração das sociedades "primitivas" como sociedades puras, nas quais se realiza o equilíbrio entre natureza e cultura, nas quais as relações humanas são visíveis em sua instantaneidade e simplicidade. Essa crítica do originário se adapta de fato bastante bem e diretamente a Lévi-Strauss, com a sua apologia das "sociedades frias" dos selvagens em relação às "sociedades quentes" tecnológicas do mundo ocidental. De maneira mais geral, Althusser vê no mito da origem o mito da realidade originária, por sua vez reconduzível a uma concepção ideológica de realidade e de praxis. A idéia, por exemplo, de que o conhecimento atual seja o resultado de um processo que parte da realidade mesma. Assim, por exemplo, a prática concreta dos agrimensores com relação à geometria euclidiana será relacionada a uma continuidade de sentido, que esconde uma filosofia da história e uma teleologia, cuja matriz remonta à racionalidade iluminista, e cuja sistematização ocorre na forma hegeliana do desenvolvimento do conceito. Mas a história do conhecimento deve antes de mais nada ser compreendida como "separada da descontinuidade real (por exemplo quando uma nova ciência se destaca do fundo das formações ideológicas anteriores), por remanejamentos profundos que, embora respeitando a continuidade da existência das regiões do conhecimento (porém nem sempre é este o caso), dão lugar, com a sua ruptura, ao reinado de uma nova lógica que, longe de ser o simples desenvolvimento, a 'verdade' ou a 'inversão' da velha, literalmente Ihe toma o lugar" . O originário, portanto, continuaria a agir como referência ideológica, para a qual o processo do conhecimento, mais do que como produção - enquanto tal, entendida em sua acepção mais ampla, a produção nunca é garantida -, é entendido como expressão: "um originário real, concreto, vivo, é encarregado de tomar a si para sempre a responsabilidade integral pelo efeito de conhecimento sobre o qual as ciências, em toda a sua história e ainda hoje, não fazem outra coisa senão comentar a herança, isto é, sofrê-la"7. Tal concepção pode assumir diversas formas, por exemplo aquela do mundo "pré-reflexivo" da "vida" de Husserl, mas recai sempre em última análise na ideologia empirista da tangência, ou melhor ainda da identidade entre o conhecimento e a realidade, entre o sujeito e o objeto. Neste caso, trata-se da identidade originária, sustentada por sua vez pelo conceito de mediação que, no entanto, observa Althusser, aparece num espaço vazio ${ }^{8}$. Isso enquadra a desconfiança althusseriana em relação ao tema da origem, manifestada no texto sobre Lévi-Strauss. De resto, nem todas as razões pelas quais Althusser ataca o mito da origem em antropologia são aplicáveis a Lévi-Strauss, estruturalista, para quem certamente a noção de origem não tem a mesma função que recebe em uma outra antropologia. Não se deve pesquisar a versão autêntica ou primitiva do mito - juntamente com a de qualquer outro fenômeno cultural - para interpretá-lo. É necessário ao contrário considerá-lo como o conjunto de suas variantes e, através da análise estrutural, descobrir-lhe a lógica interna. ${ }^{9} \mathrm{~A}$ do mito da origem é portanto uma polêmica que vai além de Lévi-Strauss. Em Lire le Capital, de fato, o exemplo contemporâneo de Althusser 
sobre isso é Sartre ${ }^{10}$, a cuja razão dialética Lévi-Strauss endereça uma crítica, em La Pensée Sauvage, que talvez não esteja distante desta althusseriana, e que termina assim: "chega-se ao paradoxo de um sistema que invoca o critério da consciência histórica para distinguir os 'primitivos' dos 'civilizados', mas que - ao contrário do que pretende - é ele próprio a-histórico: não nos oferece uma imagem concreta da história, mas um esquema abstrato dos homens que fazem uma história tal como pode manifestar-se em seu devir, sob a forma de uma totalidade sincrônica. Portanto, está situado em face da história, tal como os primitivos o estão perante o eterno passado: no sistema de Sartrre, a história desempenha o papel de um mito"11. Encontra-se aqui clara a revelação do caráter antinômico do conhecimento histórico entendido como conhecimento de um contínuo, assim como a tomada de distância em relação à consciência ingênua que vê no fato histórico um dado, quando ele ao contrário aparece claramente constituído através da abstração ${ }^{12}$. Como para Althusser, a história para Lévi-Strauss não acontece de modo necessário, nem contínuo, mas em "saltos", em "pulos": não se vai sempre adiante na mesma direção; acontece na história como o cavalo no jogo de xadrez, que realiza progressões, porém nunca no mesmo sentido; ou, ainda, o progresso não consiste em subir os degraus de uma escada um depois do outro, mas "evoca antes o jogador, cuja chance está dividida em muitos dados e que, cada vez que os lança, os vê se espalharem no pano, ocasionando contas bem diferentes. $O$ que se ganha num lance se arrisca a perder no outro, e é apenas de um tempo a outro que a história é cumulativa, isto é, que as contas se somam para formar uma combinação favorável"13. Mesmo quando, tirando as somas das análises críticas do mito da origem, Althusser escreve: "não é a gênese histórica das categorias, nem a sua conexão com as formas precedentes, que nos fornecem a sua compreensão, mas sim os sistemas de sua conexão com a sociedade atual que nos permitem também a compreensão das formações passadas, dando-nos o conceito da variação dessa conexão. Da mesma maneira, só a explicação do mecanismo do efeito de conhecimento atual é que pode nos esclarecer sobre os efeitos precedentes. A recusa em recorrer à origem está portanto correlacionada a uma exigência teórica muito profunda que faz a explicação das formas mais primitivas depender do modo de conexão sistemática atual das categorias que se encontram, em parte, nas formas precedentes". ${ }^{14}$ Aqui também encontramos um ponto de contato entre Althusser e Lévi-Strauss, porque ambos são anti-historicistas - na verdade, porque ambos são estranhos ao modelo historicista do desenvolvimento contínuo e homogêneo -, sobre a necessidade da compreensão do conhecimento atual da estrutura, para aplicar depois o tal "efeito de conhecimento" àquelas precedentes. Althusser afirma que Marx "considera a sociedade atual (e qualquer outra forma de sociedade precedente) ao mesmo tempo como um resultado e como uma sociedade"15: em $O$ Capital, portanto, embora sabendo que a sociedade atual é um resultado, um produto, Marx ocupa-se deste produto, e estuda a estrutura desse determinado modo de produção ${ }^{16}$. É verdade, contudo, que Lévi-Strauss é incidentalmente apontado por Althusser como exemplo daquele tipo de distinção entre sincronia e diacronia que revelaria a concepção hegeliana de um tempo histórico contínuo, homogêneo, contemporâneo a si mesmo. Concepção em que a relação entre o sincrônico - a contemporaneidade mesma, o conceito fundante - e o diacrônico - que não é outra coisa senão o futuro dessa contemporaneidade na continuidade homogênea do tempo - se funda sobre uma representação ideológica do tempo ${ }^{17}$. Lévi-Strauss é levado, de fato, a uma "reflexão laboriosa" para resolver os "problemas terríveis" ligados ao projeto de uma "história estrutural"18. 
Isso se deve, em última análise, à razão, já indicada, da falta em Lévi-Strauss da teoria dos modos de produção. A concepção de história de um pensador está ligada à sua concepção da totalidade socia/ ${ }^{19}$. Isso vale para Hegel, para Marx, e portanto também para Lévi-Strauss. Althusser não pode concordar com essa conclusão de Lévi-Strauss: “Basta reconhecer que a história é um método ao qual não corresponde um objeto específico e, por conseguinte, recusar a equivalência entre a noção de história e a de humanidade [...] a história não está ligada ao homem nem a nenhum objeto particular. Ela consiste, inteiramente, em seu método, cuja experiência prova que é indispensável para inventariar a integralidade dos elementos de uma estrutura qualquer, humana ou nãohumana"20. Althusser não pode concordar com essa conclusão, porque a história não tem apenas um método, mas também um objeto, a história é, com Marx, a história dos modos de produção. Um fato histórico é um fato que traz uma mudança nas relações estruturais existentes, assim como o tempo específico da produção econômica deve ser construído a partir da própria estrutura da produção ${ }^{21}$. Na passagem citada de La Pensée Sauvage, confirma-se toda a estraneidade da antropologia estrutural em relação ao pensamento marxista. Da mesma forma, em "Histoire et Ethnologie", Lévi-Strauss prevê uma integração dos resultados das pesquisas sobre as sociedades complexas e sobre as sociedades "primitivas", a fim de que se possam formular conclusões válidas universalmente, seja do ponto de vista sincrônico seja do diacrônico. Nesse caso, a sociologia não seria mais a disciplina encarregada de uma série de pesquisas empíricas sobre a organização e o funcionamento, sobretudo das sociedades de tipo mais complexo, para tornar-se uma ciência social no sentido mais amplo e compreensivo (incluindo, a saber, a etnografia e a etnologia) ${ }^{22}$. O problema da unidade da ciência das formações sociais se dá, portanto, para Lévi-Strauss, ao final da pesquisa; para Althusser deve, ao contrário, ser resolvido no começo, justamente porque a ciência das formações sociais não pode ser senão a ciência dos modos de produção. A severidade do julgamento de Althusser sobre Lévi-Strauss depende, portanto, da falta de um fundamento epistemológico efetivo da antropologia de LéviStrauss - de fato, a genericidade do ser marxista por parte de Lévi-Strauss -, que a torna filosoficamente ingênua, e do momento em que a ingenuidade assume acriticamente as evidências do senso comum, ela é ideológica. Em Sur Lévi-Strauss, Althusser critica no antropólogo francês o fato de não ver que sob as relações de parentesco estão as ações das relações de produção, e é por isso que, nas sociedades "primitivas", as relações de parentesco desenvolvem um papel tão relevante, a saber, justamente o papel das relações de produção. Maurice Godelier - o qual, não obstante, convencido da possibilidade de uma integração fecunda entre estruturalismo e marxismo, aceitava em substância, também sobre esse ponto, o pensamento de Lévi-Strauss - já o havia notado, quando dizia: "nas sociedades primitivas as relações de parentesco funcionavam diretamente, internamente como relações de produção e forças produtivas, ainda que funcionando igualmente como relações políticas e como 'armadura sociológica' do 'pensamento selvagem', código ideológico que serve de forma de expressão da vida social e que organiza as representações míticas das relações entre o homem e a natureza"23. Sobre o problema das conexões entre relações de parentesco e relações de produção, nos é particularmente interessante a posição de Emmanuel Terray, porque ele tenta desenvolver justamente as indicações que Althusser dá a esse respeito em Sur Lévi-Strauss, integrando-as com os resultados de Lire le Capital. Primeiramente, comentando a afirmação de Lévi-Strauss, para quem as normas que regulam o parentesco e o matrimônio têm "um valor operacional comparável àquelas dos fenômenos econômicos para a nossa sociedade"24, Terray escreve: "Por essa razão o etnólogo deveria substituir 
a análise da infra-estrutura econômica por aquela das relações de parentesco, uma vez que somente ela permitiria explicar a 'estrutura profunda' das sociedades primitivas. Estas não seriam mais da competência do materialismo histórico e a autonomia do antropólogo social seria assim legitimada pela irredutível especificidade de seu objeto. Quanto às atividades econômicas, elas seriam reorientadas, com muitas outras atividades, no quadro fixado pelas relações de parentesco [...] limitar-nos-emos a notar que a supremacia das relações de parentesco no conjunto da organização social não é de fato um traço comum a todas as formações econômico-sociais primitivas; ela é ligada a alguns modos de produção determinados"25. Lévi-Strauss deveria fazer com o "parentesco" o que fez com o "totemismo", mostrar como o parentesco é uma unidade nominal mais do que uma unidade objetiva em diferentes culturas ${ }^{26}$. Depois, Terray critica seja o ponto de vista que vê as relações de parentesco como "criadas" ou "geradas" pelos modos de produção, seja o ponto de vista para o qual as relações de parentesco se constituiriam de modo independente, recebendo de fora determinadas funções econômicas, jurídicas, políticas ou religiosas, acrescidas em relação às suas próprias funções, cujo exercício não as modificaria de fato. Esta última é a posição de Godelier, que sustenta que as relações de parentesco funcionam como relações de produção da mesma forma que funcionam como relações políticas, religiosas etc; o parentesco seria assim ao mesmo tempo estrutura e superestrutura. Mas, para Terray: "Ficar nisso significa simplesmente enunciar em novos termos a polivalência funcional das instituições 'primitivas' reconhecida já no tempo da antropologia clássica e concordar de fato com a posição estruturalista"27. É necessário, ao contrário, "demonstrar como a instância econômica, a instância políticojurídica e a instância ideológica transformam essa matéria [aquilo de que são feitas as relações de parentesco] para torná-la capaz de assumir as diversas funções que lhe competem, levando em conta o grau de desenvolvimento da base econômica [...] Dessa análise resulta que o 'parentesco' não pode ser considerado como uma instância particular, característica dos modos de produção 'realizados' nas formações econômico-sociais 'primitivas'. Nestas, encontramos o mesmo sistema de instâncias dos modos de produção escravagista, feudal e capitalista estudados por Marx. Qual é, definitivamente, o estatuto teórico do parentesco, nessas formações? Este último constitui um caso típico de sobredeterminação conforme o sentido que Althusser dá a esse termo"28. Assim como as classes sociais, as relações de parentesco são "o efeito complexo do jogo combinado das instâncias econômicas, políticojurídicas e ideológicas do modo de produção"29, tendo presente porém aquilo que Althusser observa em Sur LéviStrauss, isto é, que "toda formação econômico-social deve aparecer como uma combinação complexa de vários modos de produção"

Em Lire le Capital, observa que as relações de produção de um modo de produção se referem à totalidade dos diferentes níveis de uma sociedade. A esse respeito, é necessário observar que "se, como freqüentemente diz Marx, aquilo que está escondido na sociedade capitalista é claramente visível na sociedade feudal ou mesmo na comunidade primitiva, é apenas nestas últimas sociedades que vemos claramente que o econômico não é diretamente visível de modo claro! Da mesma forma que vemos também claramente que nessas mesmas sociedades o grau de eficácia dos diferentes níveis da estrutura social não está perfeitamente visível! Os antropólogos e os etnólogos 'sabem' sobre o que se basearem quando, procurando o econômico, acabam nas relações de parentesco ou nas instituições religiosas ou em outra coisa" ${ }^{13}$. Segue-se daí que "não é possível nas sociedades primitivas considerar um certo fato, ou uma certa prática aparentemente sem relação com a 'economia' (como as práticas às 
quais dão lugar os ritos de parentesco ou de religião, ou ainda as relações entre grupos na concorrência do 'potlach') como rigorosamente econômicos, sem ter construído previamente o conceito da diferenciação da estrutura do todo, nessas diversas práticas ou diversos níveis, sem ter descoberto o seu sentido próprio na estrutura do todo, sem ter identificado na diversidade desconcertante dessas práticas o espaço da prática econômica [...] o econômico, não mais que uma outra realidade (política, ideológica, etc.) não se vê nunca claramente, não coincide com o 'dado'"'32. É justamente isso que Lévi-Strauss não sabe e não faz, quando trata das relações de parentesco segundo uma lógica combinatória formal totalmente abstrata, não construindo o conceito do próprio objeto segundo uma perspectiva marxista, na qual o "econômico" detém uma função de todo prioritária.

Há um texto no qual Lévi-Strauss é solicitado a pronunciar-se sobre o caráter do próprio marxismo. Tratase da entrevista feita por Paolo Caruso em 1963, à época da publicação de La Pensée Sauvage. Interpelado por Caruso sobre a relação entre antropologia estrutural e marxismo, Lévi-Strauss afirma: "o marxismo, pelo menos aquele que tem um papel importante no meu pensamento, influi sobre a ciência enquanto filosofia do conhecimento e é, nesse sentido, completamente dissociado de qualquer ação prática ou política". À sucessiva pergunta do entrevistador: "Em que consiste, então, o seu marxismo?", Lévi-Strauss responde: "Pode-se reduzir a um certo número de proposições elementaríssimas, e são, que o homem está no mundo, que o homem pensa o mundo, e que entre todos aqueles sistemas de restrições mentais que procuro descrever com base na observação dos sistemas sociais aí encarnados, os primeiros que encontramos provêm do fato de que o pensamento humano não se manifesta nunca no absoluto, mas sempre em relação a uma certa ordem de restrições, que são em primeiro lugar restrições externas". E ainda: "o meu marxismo, diferente daquele de Marx, é um marxismo pessimista. Na medida em que sou levado a especular sobre o movimento complexo da humanidade - coisa que freqüentemente hesito em fazer - vejo-o proceder no sentido oposto àquele do esquema marxista. No fundo, quando Marx fala das 'sociedades primitivas' [...] como primeira fase no desenvolvimento da humanidade, aquela na qual a sociedade é inteiramente regida pelos próprios determinismos internos (relações de parentesco, de cosangüinidade, etc.) e a distingue da fase sucessiva, na qual, com o aparecimento das classes, as relações de produção e de troca tornam-se determinantes, vê nessa passagem um progresso. Eu, ao contrário, vejo a humanidade evoluir não no sentido de uma liberação, mas, direi sem dúvida, de uma submissão progressiva e cada vez mais concreta do homem ao grande determinismo natural. Parece-me que, seja aquilo que podemos reconstruir de épocas antigas da humanidade, seja o que podemos ainda estudar nas sociedades ditas 'primitivas', demonstra que se tratam de sociedades ainda bastante livres em relação ao determinismo natural, no sentido em que o homem e as condições de sua existência são ainda essencialmente determinadas pelos seus sonhos, pelas suas especulações, e que, por causa do baixo nível econômico, o homem goza, em relação à natureza, de uma autonomia muito maior em relação àquela que não terá em seguida. Na seqüência, de fato, assistimos a um progressivo refreamento do movimento da humanidade através de uma série de intermediários, que são aqueles descritos pelo materialismo dialético, e me parece que aquilo que está ocorrendo e ocorrerá cada vez mais é a 'apreensão direta' com a qual a humanidade é regulada pelos grandes determinismos de ordem biológica e demográfica. $O$ futuro da humanidade será aquele de uma sempre mais completa escravidão à 'fatalidade' da sua natureza" ${ }^{\prime 3}$. Lévi-Strauss vê portanto uma convergência entre a lição marxista e a freudiana, mas a vê nestes termos: "Ele [Freud] me ensinou antes de 
mais nada a crítica do significado, para a qual nenhum significado deve ser considerado como se apresenta, uma vez que por trás dele há um outro que se esconde, e atrás desse outro, um terceiro, e assim por diante, até que estejam juntos para enuclear o verdadeiro significado, que não é aquele sobre o qual os homens têm consciência. E essa foi para mim uma espécie de confirmação daquilo que o marxismo já me havia ensinado: que os homens são sempre vítimas de enganos seus ou de outrem, e que se queremos nos ocupar de ciências humanas, é preciso começar com a recusa de nos deixarmos enganar ${ }^{34 "}$. Em nome da exigência de um novo rigor, equivalente àquele das ciências naturais, no âmbito das ciências humanas, e pelo desinteresse declarado em relação à questão da praxis, Lévi-Strauss chega a evitar o confronto com o marxismo como ciência. O marxismo de Lévi-Strauss aparece assim como qualquer coisa de genérico, relegado ao terreno das questões filosóficas que constituíram os seus primeiros estudos, mas que, insatisfeito, abandonou pela etnologia, e nunca mais foi efetivamente recuperado no plano da nova cientificidade que vinha elaborando em antropologia. Contudo, a antropologia de Lévi-Strauss, quando precisa encontrar um fundamento para o formalismo inconsciente de seu estruturalismo, se orienta para entidades como o "espírito" ou o "cérebro", manifestando a adesão e a oscilação entre orientações filosóficas tão diversas quanto o neokantismo ou mesmo o cientificismo positivista. A esse respeito, veja-se que vieses podem tomar questões teóricas bastante abstratas e gerais: "Hoje podemos observar não tanto a contraposição de um homem, por um lado, e do mundo, de outro, quanto um homem que já se encontra objetivamente mediado em relação ao mundo dos próprios instrumentos de que dispõe para pensar o mundo, isto é, por exemplo, da estrutura de seu cérebro, cuja primeira restrição à qual é submetido não é aquela do 'mundo', mas aquela que resulta da anatomia, da fisiologia" ${ }^{\prime \prime 3}$.

De fato, se se lê um dos ensaios em que é mais claramente formulada a natureza da abordagem estruturalista da antropologia em relação à história, "Histoire et Ethnologie", não se pode deixar de apreciar o valor da crítica de Althusser. Lévi-Strauss observa que é necessário extrair da realidade manifesta a lógica inconsciente, exatamente como um lingüista extrai das palavras a realidade fonética do fonema. Não compara nunca portanto, nas línguas, as palavras, mas os fonemas, ou na verdade, não compara os indivíduos, mas o elemento inconsciente que torna possível a comparação, a identidade profunda. O problema é que Lévi-Strauss infere daí uma "atividade inconsciente do espírito" que impõe "formas" a um "conteúdo": enquanto as formas são imutáveis para todos os indivíduos de todas as épocas, os conteúdos variam. Lévi-Strauss aponta assim um dualismo, de tipo neokantiano, no qual o aspecto empírico, o "conteúdo", de uma pesquisa se encontra de todo desvalorizado. De fato, "é preciso e basta atingir a estrutura insconsciente, subjacente a cada instituição ou a cada costume, para obter um princípio de interpretação válido para outras instituições e costumes". Trata-se exatamente de "encontrar, por detrás do caos das regras e costumes, um esquema único"36. Isso comporta porém a anulação da história na lógica, a história não participa de forma alguma na constituição das estruturas que nela operam. Veja-se a seguinte passagem: “guerras, migrações, cismas religiosos, pressão demográfica e disputas de prestígio fazem desaparecer clãs e aldeias, ou suscitam o aparecimento de novos grupos. E apesar disso [...] o caráter formal se mantém através de todas as vicissitudes" ${ }^{\prime \prime 7}$. Qual é a relação histórica entre o caráter formal do espírito e as vicissitudes indicadas? Se Lévi-Strauss promete dar "uma arquitetura lógica a desenvolvimentos históricos que podem ser imprevisíveis, sem nunca ser arbitrários" ${ }^{\prime 38}$, não explica nada sobre qual seja a relação efetiva entre lógica e história, entre a história 
e a sua lógica. A história, ao contrário, deveria ser compreendida através de uma lógica própria, que é de fato a mesma das suas vicissitudes. O dualismo de Lévi-Strauss aparece assim como de tipo ontológico e nos relembra velhos esquemas idealistas e neokantianos, onde o dualismo entre questões históricas e estruturas que nelas agem é recomposto se temos de um lado uma teoria dos níveis sociais e, de outro, a contraposição metodológica heurística entre fatos e categorias científicas. Lévi-Strauss ataca o evolucionismo e sustenta que as culturas não são comparáveis entre si segundo escalas evolutivas, já que toda hierarquia é sempre construída a partir de uma perspectiva arbitrária. Referindo-se certamente a Leslie White, coloca em questão o critério da quantidade de energia pró-capite ${ }^{\mathrm{NT}}$, enquanto etnocêntrico, relativo à civilização ocidental, na qual, no curso dos últimos três séculos, as máquinas tiveram um papel fundamental. Se se parte de outras perspectivas, haverá diferentes classificações das culturas, e Lévi-Strauss indica várias. Trata-se sempre, no entanto, de elementos ou de partes extraídas de um complexo. Não é então o caso de tomar o caminho da comparação, mas aquele da compreensão da peculiaridade e originalidade das opções de cada sociedade, da qual é necessário desvelar as origens secretas. ${ }^{39}$ Lévi-Strauss percorre o caminho do relativismo até um certo ponto, para alcançar depois a descoberta da estrutura profunda, lógica e inconsciente, comum e latente sob as práticas sociais dos homens. A falta de relação conduz assim à identidade de um fundo lógico não atingível diretamente sobre o plano dos acontecimentos. Daí a filosofia do "espírito", ou a referência última ao "cérebro". Não se vai mais além. Por outro lado, se Lévi-Strauss tivesse querido mesmo contestar o evolucionismo, não deveria ter confrontado Leslie White, mas a tese marxista que atribui um papel fundamental ao desenvolvimento das forças produtivas e ao crescimento da produtividade do trabalho ${ }^{40}$. Tese que, bem entendido, não coincide com o ponto de vista marxista tout court e, marcadamente, não coincide com a posição marxista de Althusser. É interessante relatar também o que escreveu Lucien Sève, no mesmo ano de 1967 que é também o ano de Sur Lévi-Strauss: "Aqui se vê bem como o método estruturalista conduz, por seu apego à separação entre o sincrônico e o diacrônico e à invariabilidade própria das estruturas, não apenas a repudiar a dialética, mas também, pela sua insistência em opor as relações externas e os limites à unidade interna dos contrários e à interpenetração das contradições, através da autonomeação das estruturas que tendem a se tornarem unidades metafísicas, ao esvaziamento do próprio materialismo. Em relação a isso, seria preciso indubitavelmente analisar, com muito maior atenção crítica do que fizeram até agora os marxistas, a tese capital de Lévi-Strauss sobre a dicotomia fundamental entre o que ele chama de as ciências sociais e as ciências humanas [...] As ciências sociais, como a economia política, colocariam os problemas sobretudo sob o ângulo da intervenção prática mas não teriam suporte teórico; no oposto, as ciências humanas, terreno eleito pelo método estruturalista, constituiriam o âmbito da 'pesquisa verdadeiramente fundamental' e do rigor científico [...] Com tal dicotomia, se elimina de uma penada toda a revolução intelectual operada pelo marxismo. A economia política, rebaixada ao nível do pragmatismo, é de novo radicalmente separada seja da história seja da filosofia, o homem volta a ser estranho às relações de produção e as 'ciências humanas,' em uma versão estruturalista que não faz outra coisa senão modernizar a velha tradição do idealismo sociológico francês, podem proclamar tranqüilamente que as leis universais do espírito humano conduzem o mundo." ${ }^{41}$ Althusser se colocava portanto uma questão tão viva naqueles anos, o debate do marxismo frente ao estruturalismo. Certo, a um estruturalismo histórico e humanista já correspondia um marxismo estruturalista, mas, em todo caso, e em particular depois do 
lançamento de La Pensée Sauvage, a recusa por parte de Lévi-Strauss de um critério qualquer de comparação entre as sociedades, que ligasse fortemente estrutura e história, surgia como uma tentativa de invalidar o pensamento dialético, e, com isso, as ciências sociais de matriz marxista, que a despeito da variedade de suas filiações teóricas, não podiam deixar de se sentir convocadas. Nesse debate se coloca portanto Althusser, que reivindica também ele, frente à antropologia estruturalista, o conceito marxista de "formação social", cuja complexidade - o "todo complexo estruturado dominante" marxista no lugar da "totalidade simples" hegeliana -, a partir da "tópica" marxista da estrutura e da superestrutura ${ }^{42}$, envolvia diretamente a questão da ciência e da ideologia, e portanto a crítica do humanismo. É por isso que Althusser defende a originalidade de suas próprias idéias sobre Lévi-Strauss e sobre a antropologia, as quais não refletiriam em nada o que circulava então sobre o assunto: não é só a questão do "primitivo" e do moderno, da estrutura e da história, mas, a partir da teoria da complexidade do todo social em seus níveis, é de fato a questão da ciência que deve ser posta em foco, e a antropologia tende a dissolver-se em seus elementos ideológicos característicos na medida em que decai a sua tentativa de constituir objeto que seja autônomo, outro, em relação ao objeto da história.

A operação de definição do estatuto epistemológico da antropologia ocorre, por parte de Althusser, no interior da certeza, não sei se se pode dizer iluminista, de separar ciência e ideologia. A ciência não faz parte da superestrutura, porque diferentemente da ideologia, não é guiada por "interesses" externos à necessidade do conhecimento. ${ }^{43}$ Por sua vez, a ciência nasce no interior da mesma conjuntura, do mesmo conflito teórico do qual nasce a ideologia, mas se distingue como o verdadeiro se distingue do falso. Não se trata de uma verdade que se pretende neutra, na medida em que está perfilada no interior da luta de classes. ${ }^{44}$

Em Philosophie et Philosophie Spontanée des Savants, Althusser reflete, em um plano mais geral, a respeito de questões apontadas no breve artigo sobre Lévi-Strauss e sobre a antropologia, de poucos meses antes, e mostra, nessa obra, a função da filosofia a serviço das ciências ${ }^{45}$. A relação entre a filosofia e as ciências constitui a determinação específica da própria filosofia. ${ }^{46} \mathrm{~A}$ filosofia critica, divide, traça linhas de demarcação, não substitui os cientistas mas libera-Ihes a estrada e indica dessa forma o caminho certo ${ }^{47}$, ela intervém na "teoria", ou seja, no campo das ciências, da filosofia e das ideologias teóricas, fazendo assim parte ela mesma da conjuntura em que $a^{a g} \mathrm{e}^{48}$. Nos confrontos de Lévi-Strauss e da antropologia cultural, Althusser coloca em prática exatamente aquilo que afirma a Tese 20 do "Primeiro Curso" de Philosophie et Philosophie Spontanée des Savants: "A filosofia tem como principal função traçar uma linha de demarcação entre o ideológico e as ideologias de um lado, e o científico e as ciências de outro"; ela "se define através de uma relação dupla: em relação às ciências e em relação às ideologias práticas"; "restitui uma proposição ideológica à sua 'terra de origem', a ideologia prática, portanto, a uma realidade social exterior e estranha à prática científica" ${ }^{49}$, de um lado e, de outro, intervindo no espaço em que o ideológico e o científico são indevidamente confundidos, pode liberar a prática científica do impedimento de uma dominação ideológica..$^{50}$ De fato, os próprios homens de ciência não escapam, pelo fato de fazerem ciência, ao risco de terem falsas idéias sobre a ciência, acolhendo falsas evidências que implicam soluções ideológicas para problemas científicos. ${ }^{51} \mathrm{~A}$ reflexão desenvolvida em torno da antropologia estruturalista ofereceu seguramente alguns dos elementos centrais dessa teorização que leva Althusser a colocar em relevo "a incerteza da maior parte das ciências humanas sobre o próprio estatuto teórico". A sua "impaciência generalizada de se lançarem sobre a matemática" 
é o sintoma de uma, ainda não alcançada, maturidade teórica. Trata-se de uma "doença infantil", índice de uma discordância entre as ciências humanas e o seu objeto, que fica "ao lado" delas, e talvez seja de fato inexistente: "na maior parte das ciências humanas, a inflação matematizante não constitui uma doença da juventude, mas sim uma fuga para frente a fim de compensar uma falta fundamental: salvo algumas exceções, bem definidas, as ciências humanas são ciências sem objeto (no sentido forte), elas têm uma base teórica falsa ou ambígua [...] concretamente não 'sabem' de que coisa elas são o objeto" ${ }^{\prime \prime 2}$. Althusser usa as mesmas expressões que havia usado no breve texto sobre Lévi-Strauss, dizendo que este "fazia faltar" o próprio objeto, e que havia tomado conta dele uma "fuga em direção ao alto' por obra da má formalização [lógica combinatória]", [fuite par le haut] (aqui uma "fuite en avant", aquela da "inflação matematizante" $)^{53}$. As categorias filosóficas idealistas, como as estruturalistas, utilizadas pelas disciplinas humanistas, são o substituto ideológico de uma base teórica ausente. ${ }^{54} \mathrm{~A}$ filosofia deve então distinguir, no âmbito das ciências humanas, as "verdadeiras" ciências das disciplinas que equivocadamente se pretendem científicas, e o seu fundamento ideológico de fato do fundamento teórico de direito" ${ }^{55}$. E é esse "fundamento teórico de direito" que Althusser atribui à antropologia cultural. A crítica de Lévi-Strauss se entrelaçava com aquela do estruturalismo; analogamente, aqui Althusser precisa que a filosofia que executa a demarcação entre ciência e ideologia não pode ser a mesma que é utilizada pelos estudos humanistas ${ }^{56}$. Será então tarefa de uma filosofia materialista "combater todas as formas de exploração idealista das ciências", de "conquistar para a ciência a maior parte das 'ciências humanas' e acima de tudo as ciências sociais que, salvo exceções, ocupam por imposição o continente-história, do qual Marx nos deu as chaves"57. De que modo? Controlando "por meio do conhecimento e da crítica a ligação orgânica que a reconecta às ideologias práticas" ${ }^{\prime \prime 8}$. A crítica que a filosofia executa sobre a ciência e sobre a ideologia torna-se crítica sobre a própria filosofia. De fato, as disciplinas aplicadas das ciências humanas como método universal são geralmente aplicadas de forma externa, mecânica, instrumental, técnica. É o caso do estruturalismo. Mas o ponto é que se as ciências utilizam alguma filosofia é porque elas mesmas realizam a ideologia dominante. ${ }^{59}$ As "ideologias teóricas" são de fato, "em última instância, na teoria formas transformadas de ideologias práticas". ${ }^{60}$

Uma idéia forte de ciência se conjuga com a reflexão sobre os conceitos do materialismo histórico: são estas as premissas fundamentais para compreender a posição e as indicações althusserianas com relação à antropologia cultural. Althusser fixou portanto um pressuposto teórico positivo, a concepção marxista de "formação social" como correlato da noção de modo de produção, para o qual se sente a necessidade de uma definição rigorosa - com a descoberta do "continente-História", Marx ofereceu um novo fundamento a todas as ciências sociais e humanas -, e um modelo negativo, em contraste, a antropologia estruturalista de Lévi-Strauss, através da qual Althusser entrevê a natureza ideológica da antropologia cultural, as idéias falsas sobre a ciência e sobre si mesma próprias dessa disciplina. A ela é preciso acrescentar o marxismo econômico, também ele ideológico, influenciado pela ideologia burguesa, essencialmente economicista, que impõe também aos marxistas a "falsa evidência" de que tudo depende das forças produtivas, do desenvolvimento impetuoso da ciência e da técnica - sobre o qual Althusser retorna outras vezes em suas obras. ${ }^{61}$

As indicações de Althusser permitem individualizar os vícios ideológicos de fundo da antropologia cultural através da sua própria história. Com efeito, a concepção da sociedade primitiva como sociedade "outra" remonta 
ao nascimento da antropologia cultural a partir da segunda metade do século XIX - nascimento coevo ao do imperialismo colonial contemporâneo, com o qual se recoloca com força a distinção de sociedade civil e comunidade primitiva. O modelo evolucionista unilinear de Morgan e Tylor via a diferença entre ocidentais e "selvagens" como uma diferença histórica, não natural, derivada do fato de que eles ocupavam diferentes pontos na linha da evolução. $O$ evolucionismo unilinear, não obstante, era fundamentalmente etnocêntrico, porque esse era o seu critério organizador, o progresso, a tecnologia, a concepção positivista do conhecimento ${ }^{62}$. Depois a antropologia funcionalista, no início do século XX, com Malinowski, tenderá a contrapor "selvagens" e "civilização" através do confronto entre a autenticidade das sociedades primitivas - não obstante, também elas já corrompidas pela colonização - e a degeneração das sociedades industriais. Não será, entretanto, menos etnocêntrico porque, aceita ou recusada que seja, é a mesma noção de progresso tecnológico que funciona como critério de comparação, seja para o evolucionismo, seja para o funcionalismo. Esta "falsa evidência" econômica, produto da ideologia burguesa, segunda a qual tudo depende das forças produtivas, do desenvolvimento irrefreável da ciência e da técnica, faz par com o mito da sociedade "originária". Nele Althusser certamente reencontra o mito empírico através do qual o conhecimento movimenta de uma "terra natal" própria, um "solo originário", o mundo pré-reflexivo da vida, da unidade originária e indiferenciada entre objeto e sujeito, do real e de seu conhecimento ${ }^{63}$. Mítica é também a idéia que o modo de produção de uma "sociedade primitiva" seja simples; Althusser demonstra ao contrário como ele é extremamente complexo ${ }^{64}$. É nas "sociedades primitivas" que se vê aquilo que vale para o geral, isto é, que o econômico não é um dado imediatamente claro e apreensível, assim como não o é o grau de eficácia dos diferentes níveis da estrutura social. Por isso os antropólogos partem do econômico e terminam depois por ocuparem-se das relações de parentesco, das instituições religiosas, etc ${ }^{65}$.

Dizendo com as palavras de Ernesto de Martino, “opera nessas visões nostálgicas da inocência perdida o esforço do esquecimento de si, talvez último estertor do monólogo colonialista e missionário da velha Europa"66. Não esqueçamos que as "sociedades primitivas" foram todas sociedades colonizadas, qualificadas como "primitivas" exatamente porque aptas a serem colonizadas ${ }^{67}$. No artigo sobre Lévi-Strauss, Althusser nota também, interpretando pistas, como Lévi-Strauss no fundo se dedica apenas às sociedades primitivas, uma vez que, mesmo quando se voltava para as sociedades ocidentais contemporâneas, não fazia outra coisa senão aplicar também a estas as categorias que tinha trazido do seu estudo sobre os "selvagens" ${ }^{68}$. De fato, a valorização que Lévi-Strauss faz das sociedades contemporâneas está inteira na distinção entre "sociedades quentes" e "sociedades frias", onde a falta de um critério científico de análise sobre a estrutura complexa das sociedades contemporâneas é substituída por um juízo de valor sobre a humanidade mais pura, mais autêntica, próxima à "boa" natureza dos "selvagens", aos quais não obstante se liga um saber lógico ao mesmo tempo bastante elaborado e complexo e próximo à natureza, capaz com isso de captar a propriedade das coisas, em maior medida do que é capaz de fazê-lo a ciência ocidental ${ }^{69}$. É verdade que por medo de aplicar as categorias da sociedade ocidental aos "selvagens" acabou freqüentemente por fazer o oposto. É sobre isso que se debate a tentativa de Lévi-Strauss em distinguir sociologia e antropologia, a primeira como aquela que se esforça por ser "a ciência social do observador", a segunda, ao contrário, "a ciência social do observado"70. 
A perspectiva marxista de Althusser pretende ser um modo de evitar ambas as aporias, partindo não de uma ou de outra sociedade, mas da ciência. Parece-me claro que se se segue a objeção para a qual a própria ciência não é neutra, mas um resultado da civilização ocidental, não se pode acabar senão em um relativismo sem saída. O etnocentrismo, já advertia também Ernesto de Martino, não é sobrepujado abdicando-se à razão e à ciência ocidental, mas alargando o suporte da razão de modo a evitar a insurreição do irracionalismo, ainda mais em uma época em que as distâncias entre todas as civilizações estão reduzidas, instaurando “um diálogo objetivante e uma objetivização dialogante entre o Ocidente e os outros povos e civilizações do planeta"71. Alerta-se já há tempos sobre a necessidade de repensar o objeto-história, mas o relativismo, depois das "grandes narrativas", parou de pensá-lo, anulou-o, considerando-o inexistente ou não vendo uma saída para as aporias nas quais incorriam aqueles que o utilizavam. Esta fragmentação relativista - herdeira da concentração sobre a análise sincrônica que constitui boa parte da pesquisa antropológica do século XX como reação ao evolucionismo (Boas, Lowie) e, de certa forma, o funcionalismo e o estruturalismo - é certamente a marca de uma desorientação, mas o plano teórico poderia revelar-se, também nesse caso, composto por elementos ideológicos consistentes, de uma política em seguida não tão explícita e mais ambígua, ainda que aparentemente "bem-intencionada", porque não apresenta hierarquias, ordens de sucessão, etc. Contrariamente, a unidade do objeto-história nos parece dada por Althusser através da vigorosa reproposição da noção de formação social e da sua estrutura complexa e hierárquica.

A ideologia na antropologia é a negação da diferença dos níveis da realidade social, é a sua caracterização como estruturas isomorfas, colocadas todas no mesmo plano. A questão das sociedades primitivas é então fundamental, o papel de tornassol da antropologia enquanto ideologia, exatamente porque a antropologia cultural queria fazê-las aparecerem como sociedades indiferenciadas. Ao contrário, as sociedades ocidentais seriam complexas e diferenciadas, mas, se a unidade de medida com a qual são avaliadas torna-se a natureza de suas relações com as sociedades primitivas, tal diferenciação estrutural, em virtude do contraste com a solidez simples das sociedades primitivas, não é mais questionável sob a noção de modo de produção; é indicado assim o caminho para análise de fatores comparativos abstratos: a qualidade da relação entre homem e natureza, entre indivíduos e instituições, sob a égide da noção de autêntico - "a questão da autenticidade" como a chama de fato Lévi-Strauss em uma ocasião - como plenitude da forma de vida, sociedade em relação harmônica e natural com a natureza contra sociedade desagregada e em oposição destrutiva em relação à natureza. É uma contraposição que capta sem dúvida os elementos de verdade e dos quais é difícil fugir para aquele que teve de fato uma experiência partícipe de trabalho de campo. Essa não é, contudo, na perspectiva que aponta Althusser, a colocação científica correta para a questão. Aponta-se aqui o perigo de um retorno ao Erlebnis e ao Einfühlen ${ }^{N T}$ de Dilthey, isto é, de uma identificação com o objeto, retomada depois pela antropologia religiosa de molde fenomenológico, na qual a conceitualização científica coincide com a evidência e instantaneidade da experiência do sujeito estudado (o homem religioso, as sociedades primitivas) ${ }^{72}$.

Althusser conclui então que não existem "sociedades primitivas" (tal denominação não indica nada de científico), mas existem "formações sociais", isto é, todas as sociedades, primitivas ou não, são homogêneas em relação à determinação de seu modo específico de produção. Tal conceito é separado de toda contaminação com a idéia de origem no sentido apontado, isto é, "de cultura pura nascente, de verdade das relações humanas visíveis, puras, nativas"73. Sobre essa base, se dissolve a noção de antropologia: "A antropologia não pode existir. É um 
Marco Vanzulli

conceito que retoma apenas a ideologia etnológica na ilusão de que o objeto da etnologia seja constituído por outras realidades a respeito das quais trata a ciência da história (as formações sociais, quaisquer que elas sejam) [...] a pretensão de criar conceitos específicos próprios dessa realidade única (e exemplar) que é uma sociedade primitiva, e a pretensão de criar, no interior desses conceitos, conceitos primitivos (isto é, originários) em relação a todos os conceitos no interior dos quais se pensa a realidade das outras 'formações sociais', em particular em relação aos conceitos marxistas"74. O exemplo é dado pela análise de Lévi-Strauss sobre as relações de parentesco: “Quando Lévi-Strauss analisa a estrutura, as estruturas das relações de parentesco, o que ele não diz é que se as relações de parentesco desenvolvem nas sociedades primitivas um papel tão importante é porque elas de fato fazem o papel de relações de produção, relações de produção que são compreensíveis somente em função dos modos de produção dos quais são relações de produção (e da combinação destes modos de produção). Resulta que

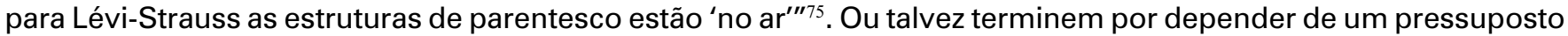
teórico de tipo funcionalista, sobre o qual se busca explicar a totalidade social através da identificação de cada instituição cultural com a resposta a uma determinada necessidade. De fato, o estruturalismo de Lévi-Strauss pode ser considerado uma revisão e uma extensão do funcionalismo, em que a função de cada instituição cultural é generalizada quase que para hipostasiar um "inconsciente social" que rege a vida social e verdadeiro objeto da pesquisa antropológica ${ }^{76}$.

Vimos as considerações do althusseriano Terray sobre o valor da "instância" das relações de parentesco. Althusser redesenha a relação entre as instâncias determinantes no interior do complexo estrutura-superestrutura, que não pode ser entendida como a inversão da filosofia hegeliana, porque não é mais exprimível em termos de fenômeno-essência. Trata-se, de fato, de uma nova relação descrita, por um lado, pela determinação em última instância por parte do econômico, e de outro, pela autonomia específica das superestruturas e de suas eficácias específicas ${ }^{77}$.

Como confirmação do fato de que não se pode partir de uma instância qualquer pretendendo, por analogia estrutural orgânica, ou pela dedução tornada possível pela premissa organicista (o todo nas partes), determinar as outras instâncias sociais, pode-se relevar que, em determinadas formações sociais, diferentes modalidades de organização social baseadas em sistemas classificatórios de parentesco permitam satisfazer a exigência de respostas institucionais ao crescimento da capacidade produtiva. Sistemas bilaterais e unilineares de parentesco são suscetíveis de ampliação a fim de aparelhar a necessidade organizacional de novas estruturas socioculturais. É por isso que faliram as tentativas de unir os modelos de parentesco classificatórios a formas progressivas de desenvolvimento sociocultural. A variedade das respostas possíveis às mesmas exigências da renovação do sistema produtivo torna difícil a construção de seqüências genéticas das formas do parentesco ${ }^{78}$. A contestação do logicismo estruturalista de Lévi-Strauss não comporta então, por isso mesmo, uma rígida correspondência entre o estrutural e o superestrutural.

A recusa da concepção da sociedade como totalidade orgânica leva a refutar a idéia que de uma simples instituição, o tipo de parentesco, se possa reconstruir a totalidade da sociedade - é o que se viu na crítica dos isomorfismos de Lévi-Strauss e da tradição da hermenêutica - tanto para as sociedades primitivas quanto para as sociedades massificadas, complexas, ou mesmo globalizadas. As sociedades se apresentam como conjuntos articulados, compostos por níveis, cada um com seu próprio tempo - entendido no sentido específico, intra-social, 
e também histórico -, que se chocam e se entrelaçam. Althusser diz de fato que não existe um tempo único entre os elementos de um modo de produção, mensurável sobre a mesma linha de um tempo de referência contínuo. Existem diversos níveis com tempos próprios - tanto na estrutura como na superestrutura -, o econômico, que por sua vez não é de fato completamente compacto, o político, o jurídico, etc. Os conceitos dos diferentes tempos históricos "são construídos a partir da natureza diferencial de seus objetos na estrutura do todo"79. Um modo de produção comporta então um entrelaçamento de tempos diferentes, no qual coexistem defasagens de desenvolvimento no presente da conjuntura ${ }^{80}$ De outro lado, Althusser não renuncia à tentativa de determinação de uma visão complexa da sociedade, a totalidade social - isto permite de fato apenas que seja respeitado antes de tudo o nexo cientificidade-objetividade -, e é isso que procura fazer, por exemplo, com as noções de causalidade metonímica, de conjuntura e sobredeterminação.

O conceito da estrutura do econômico requer que seja construído primeiro o conceito da estrutura do modo de produção (os seus diferentes níveis e as suas articulações específicas). Para cada modo de produção específico deve então ser construído o conceito de econômico específico, e assim para todos os outros níveis, o ideológico, o político, etc ${ }^{81}$. Também porque cada formação social é composta de uma pluralidade de modos de produção, dos quais um é dominante, e só assim se pode dar conta da "complexidade contraditória dos fatos empíricos observáveis no interior de cada formação social concreta, e também das tendências contraditórias que se enfrentam, e se traduzem na sua história (as suas transformações reais observáveis, na economia, na política, na ideologia)"82. Assim, Althusser dá à antropologia a chave de uma análise em condições de ligar de maneira estreita observações e descrições empíricas à construção de uma teoria; e indica a possibilidade de uma pesquisa que construa de uma sociedade (ou de uma seção da sociedade) a teoria específica do modo de produção, captando aí a unidade específica que funda a possibilidade material da combinação dos elementos que aparecem empiricamente como a separação da pluralidade das forças produtivas ${ }^{83}$.

Vimos como segundo Althusser as relações de produção de um modo de produção se referem à totalidade dos níveis distintos de uma sociedade, e como isso implica que a instância do "econômico", ainda que a sua determinação constitua sempre uma prioridade, não deve ser entendida como uma evidência. Repreensão à antropologia econômica de inspiração marxista. O econômico não é o dado, não é uma evidência, não é o ponto de partida imediatamente identificável, porque ele será compreendido no interior da relação peculiar entre forças produtivas e relações de produção em um modo de produção. A cautela que Althusser tinha no que diz respeito à definição do econômico depende do primado que atribuía à instância das relações de produção sobre a das forças produtivas - não apenas das sociedades de classe, mas de todas as sociedades -, pelo qual estas últimas devem ser inscritas nas relações de produção; não existe produção econômica pura, mas os fenômenos econômicos como processos que se desenvolvem no interior de relações sociais ${ }^{84}$. Daí a tendência de conceder, sob a égide das relações de produção, um certo primado para a organização social das forças produtivas, ou seja, à política, que pode utilizar as mesmas forças produtivas de diferentes maneiras. As mesmas forças produtivas que foram usadas pelas formações pré-coloniais serão utilizadas na cooperação do "trabalho forçado" colonial, porém com resultados de todo novos; da mesma forma, a cooperação em larga escala nas comunidades populares da China da Revolução utilizou exatamente os mesmos instrumentos de produção presentes já nas antigas formas 
Marco Vanzulli

de cooperação familiar camponesa, também aqui, com resultados em tudo diferentes; ainda, as mesmas forças produtivas geram bens agrícolas e industriais em um país capitalista ocidental, na China comunista e na União Soviética. Não é necessário o longo processo da dialética hegeliana, que está na "Introdução à Crítica da Economia Política", para que um país atrasado possa alcançar um alto nível tecnológico-produtivo e completar o próprio atraso econômico ${ }^{85}$. E, sendo calibrada sobre a antropologia estruturalista, a definição althusseriana do estatuto epistemológico da antropologia cultural talvez não se adapte tão bem, como crítica, a correntes antropológicas menos especulativas que as francesas, como a do neoevolucionismo americano. Esse de fato já executa a própria pesquisa sob a escolta da noção marxista de modo de produção e da tentativa de conhecimento global do homem que se refere a todas as sociedades humanas - mérito atribuído à antropologia dos países anglo-saxões pelo próprio Lévi-Strauss ${ }^{86}$. Althusser está, entretanto, distante do economicismo dessa antropologia, que se caracteriza pelo primado atribuído à tecnologia como fator histórico e, também, distante de uma concepção da história como um continuum homogêneo, que é também um continuum de sentido. A propósito do primado da tecnologia como fator histórico determinante, para o qual a história da evolução humana seria a história da evolução tecnológica - tese que encontra aval, entre outros, na famosa nota de $O$ Capital em que Marx prevê a necessidade de uma história crítica da tecnologia ${ }^{87}$-, Althusser parece relevar que o desenvolvimento extraordinário da tecnologia dos últimos séculos seja um efeito do modo de produção capitalista, ou seja, do modo de produção que deve "revolucionar" constantemente os meios de produção existentes. Referindo-se ao modo de produção, Althusser reenvia, portanto, decididamente ao primado das relações de produção sobre as forças produtivas - no interior, bem entendido, de sua unidade ${ }^{88}$.

Althusser retoma então em Lévi-Strauss a falta de uma teoria dos modos de produção e desenvolve diretamente algumas considerações críticas sobre o caráter ideológico da antropologia cultural. Assim, o problema do estatuto epistemológico da antropologia - o que é uma sociedade? - é transferido para a espinhosa questão (questão tornada espinhosa sobretudo no interior do debate marxista nos anos sessenta e setenta) - o que é uma formação social? O que é um modo de produção? De fato, uma vez tomada, como ideológica, pela antropologia cultural a especificidade do próprio objeto, a pars construens ${ }^{N T}$ da reflexão althusseriana sobre este tema desemboca na tentativa de determinação teórica da totalidade social. Esta será pesquisada ainda em uma nova problematização da teoria dos modos de produção, através da qual se redefine a relação entre as instâncias sociais como articulação complexa individualizada e específica. As diferentes instâncias sociais, de um lado, estão entre elas conforme uma relação não paralela mas hierárquica, e, de outro, são consideradas não como estruturas isomorfas, mas como estruturas formalmente diferenciadas, segundo uma linha de relativa autonomia, sob a égide das relações de produção, que a cada instância reconhece uma existência e uma temporalidade próprias no interior da totalidade social.

Tradução: Lígia Negri (Departamento de Lingüística, Letras Clássicas e Vernáculas da Universidade Federal do Paraná). 


\section{NOTAS}

1 L. Althusser, "Sur Lévi-Strauss", in Écrits Philosophiques et Politiques, éd. F. Matheron, Paris, Stock-IMEC, 1994, tomo II, pp. 417432; tr. it. a cargo de M. Vanzulli in L. Althusser Su Feuerbach. In Appendice Su Lévi-Strauss, Milão, Mimesis, 2003, pp. 93-105.

2 L. Althusser, "Sur Feuerbach", in Écrits Philosophiques et Politiques cit., tomo II, pp. 169-251; tr. it. de M. Vanzulli, L. Althusser, Su Feuerbach. In appendice Su Lévi-Strauss cit., pp. 31-90.

3 Idem, pp. 223-224; tr. it. cit., p. 74, Chi causa che cosa. É um pouco a crítica que foi endereçada ao funcionalismo em antropologia, por exemplo, por Julien Steward ao expor, no interior da sua concepção de evolução multilinear, a teoria da ecologia cultural. Steward notava que se explica pouco sobre uma cultura quando todos os seus elementos são considerados ao mesmo tempo causa e efeito (cf. J.H. Steward, Theory of Cultural Change. The Methodology of Multilinear Evolution, Urbana, University of Illinois Press, 1955).

4 L. Althusser, "Sur le Jeune Marx", in Pour Marx, Paris, Maspero, 1965, p.59.

5 L. Althusser, "La Reproduction des Rapports de Production", in Sur la Reproduction, Paris, PUF, 1995, pp. 41-42.

6 L. Althusser-E. Balibar, Lire le Capital, Paris, Maspero, 1975(1968), vol. I, pp. 51-52. É também verdadeiro, porém, que “não se rompe de um golpe com um passado teórico: são necessários conceitos e palavras para romper com outras palavras e outros conceitos, e são freqüentemente as velhas palavras a serem investidas do protocolo da ruptura, por todo o tempo que dura a pesquisa das novas" (L. Althusser, Pour Marx, cit., p. 28).

7 L. Althusser - E. Balibar, Lire le Capital, cit., vol.I, p. 76.

8 Idem, vol.I, pp. 51-52 e 75-78.

9 C. Lévi-Strauss, "La Structure des Mythes", in Anthropologie Structurale, Paris, Plon, 1958, p.240.

10 L. Althusser - E. Balibar, Lire le Capital, cit., vol. I, p. 77.

11 C. Lévi-Strauss, La Pensée Sauvage, Paris, Plon, 1962, pp. 302-303 [N.E.: edição brasileira, O Pensamento Selvagem. Campinas: Papirus, p. 282. Tradução: Tânia Pellegrini].

12 Idem, pp. 306-310.

13 C. Lévi-Strauss, Race et Histoire, in VV.AA., Le Racisme Devant la Science, Paris, Unesco, 1973 (1960), pp. 23-24 [N.E.: edição brasileira, "Raça e História", in Antropologia Estrutural II, Rio de Janeiro, Tempo Brasileiro, pp. 343. Tradução: Chaim Samuel Katz].

14 L. Althusser - E. Balibar, Lire le Capital, cit. vol. I p.78.

15 Idem, vol. I, p. 80.

16 Ibidem.

17 Idem, vol. I, p. 119

18 Idem, vol. I, p.135.

19 Idem, vol. I, p.120.

20 C. Lévi-Strauss, La Pensée Sauvage, cit., pp. 312-313 [N.E.: tr. bras. cit., p. 290-91].

21 L. Althusser - E. Balibar, Lire le Capital, cit., vol. I, pp. 127 e 125-126.

22 C. Lévi-Strauss, "Histoire et Ethnologie", in Anthropologie Structurale, cit., pp. 4-5.

23 M. Godelier, "Logica Dialettica e Analisi delle Strutture", in M. Godelier - L. Sève, Marxismo e strutturalismo, Turim, Einaudi, 1970, pp. 107-108. Cf. também: "Pode-se supor que o desenvolvimento das forças produtivas nas sociedades primitivas tenha tornado cada vez mais difícil e inútil o domínio das relações de parentesco sobre a vida social" (idem, p. 109), e: "Mas em uma sociedade 


\section{Marco Vanzulli}

arcaica as relações de parentesco funcionam como relações de produção da mesma forma que funcionam como relações políticas. Portanto, na linguagem de Marx, as relações de parentesco são aqui ao mesmo tempo infraestrutura e superestrutura e pode-se supor que a complexidade das relações de parentesco nas sociedades arcaicas esteja em relação com as múltiplas funções que elas realizam nesse tipo de sociedade. Pode-se igualmente supor que o papel dominante e a estrutura complexa das relações de parentesco nas sociedades arcaicas estejam relacionados com a estrutura geral das forças produtivas, com o seu baixo nível de desenvolvimento que impõe a colaboração entre os indivíduos, portanto com a vida em grupo para subsistirem e reproduzirem-se [...] Portanto, na medida em que, nesse tipo de sociedade, o parentesco funciona realmente como relações de produção, o papel determinante da economia não viria contradizer o papel dominante do parentesco mas sim exprimir-se através dele" (M. Godelier, "Système, Structure et Contradiction dans Le Capital", Les Temps Modernes, p. 246 (1966), pp. 860-862; tr. it. a cargo de M. Minerbi, in M. Godelier - L. Sève, Marxismo e Strutturalismo, cit., pp. 44-46).

24 C. Lévi-Strauss, entrevista a Témoignage Chrétien, 18 abril de 1968, p.18.

25 E. Terray, "Le Matérialisme Historique devant les Sociétés Segmentaires et Lignagères", in Le Marxisme devant les Sociétés "Primitives", Paris, Maspero, 1969, pp. 134-135.

26 Idem, pp. 135-136.

27 Idem, pp. 137-138.

28 Idem, p. 138.

29 Idem, p. 139.

30 Idem, p. 168.

31 L. Althusser - E. Balibar, Lire le Capital, cit., vol. II, pp. 50-51.

32 Idem, vol. II, p. 51-52.

33 P. Caruso, "Intervista a Claude Lévi-Strauss", Aut Aut 77 (1963), pp. 31-33.

34 Idem, p. 41.

35 Idem, p. 33.

36 C. Lévi-Strauss, "Histoire et Ethnologie", cit., p. 28 [N.E.: edição brasileira, "Introdução: História e Etnologia", in Antropologia Estrutural, Rio de Janeiro, Tempo Brasileiro, pp. 37-38. Tradução: Chaim Samuel Katz e Eginardo Pires. Revisão etonológica de Júlio Cezar Melatti]. Emmanuel Terray, influenciado exatamente por Althusser, de quem conhecia, como já vimos, também o escrito sobre Lévi-Strauss, considerava o estruturalismo do próprio Lévi-Strauss "imóvel" e "raso": "Todos os níveis são colocados em um plano de estreita igualdade, uma vez que as estruturas que eles revelam são, todas do mesmo modo, o produto da atividade lógica inconsciente do espírito humano [...] Porque não são processos reais, mas correlações lógicas, as transformações que permitem passar de um nível ao outro são reversíveis: o sistema pode ser percorrido por qualquer um de seus elementos [...] o seu [dos estruturalistas] escopo é descobrir correspondências formais entre as estruturas: homologia, isomorfia, simetria, inversão, estes são os conceitos de que se servem para descrever essas correspondências. Assim a sociedade aparece em seus diversos níveis como um sistema de espelhos que se reenviam uns aos outros a própria imagem mais ou menos deformada. Tal concepção não pode dar lugar ao acontecimento, à mudança" (E. Terray, "Morgan et l'Anthropologie Contemporaine", in Le Marxisme devant les Sociétés "Primitives", cit., pp. 44-45).

37 C. Lévi-Strauss, “Histoire et Ethnologie”, cit, p. 29 [N.E.: tr. bras. cit., p. 38].

38 Idem, pp. 30-31 [N.E.: tr. bras. cit., p. 39].

NT Pro capite: em favor do indivíduo.

39 C. Lévi-Strauss, Race et Histoire, cit., pp. 28-30 [N.E.: tr. bras. cit., p. 349]. 
que representa o estado o mais e melhor elaborado do pensamento científico, quer dizer, a tese marxista que, em última análise, no interior da determinação das estruturas não-econômicas da sociedade pela estrutura econômica, atribui um papel fundamental ao desenvolvimento das forças produtivas, ou, mais precisamente talvez, ao crescimento da produtividade do trabalho. Nível das forças produtivas, grau de produtividade do trabalho, isso existe, isso se mede - e é, de longe, determinante - em toda sociedade, qualquer que seja, sociedades primitivas ou outras" (C. Parain, "Struturalisme et Histoire", La Pensée 135 (1967), p. 49).

41 L. Sève, “Méthode Structurale et Méthode Dialectique”, La Pensée 135 (1969), pp. 86-87.

42 L. Althusser, Est-il Simple d'Être Marxiste en hilosophie?, cit., pp. 14-16 e 10-11.

43 L. Althusser, “L'Objet du Capital”, in L. Althusser - E. Balibar, Lire le Capital cit., vol. I, pp. 169-170 e 181.

44 L Althusser, Apêndice B de Leggere il Capitale, tr. de R. Rinaldi e V. Oskian, Feltrinelli, Milão 1971 (1968), p. 352.

45 L Althusser, Philosophie et Philosophie Spontanée des Savants, Paris, Maspero, 1974, p. 11.

46 Idem, p. 65.

47 Idem, pp. 15 e 34.

48 Idem, pp. 61 e 59.

49 Idem, pp. 26-27.

50 Idem, p. 50.

51 Idem, p. 34.

52 Idem, p. 36.

53 L. Althusser, Sur Lévi-Strauss cit., pp. 418-419 e 427.

54 L Althusser, Philosophie et Philosophie Spontanée des Savants cit., p. 38. Cf. L. Althusser - E. Balibar, Lire le Capital cit., vol. I, p. 135, sobre a "laboriosa reflexão" à qual Lévi-Strauss é levado para resolver os "problemas terríveis" ligados ao projeto de uma "história estrutural".

55 L Althusser, Philosophie et Philosophie Spontanée des Savants cit., p. 39.

56 Idem, p. 39.

57 L Althusser, Apêndice B de Leggere il Capitale, cit. p. 350.

58 L Althusser, Philosophie et Philosophie Spontanée des Savants cit., pp.113-114.

59 Idem, pp. 45-46.

60 Idem, p. 62.

61 Cf. idem, p. 243. Cf. também a crítica da concepção ideológica segundo a qual as relações da divisão e da organização do trabalho seriam essencialmente "técnicas" (pp. 58-71).

62 Cf. Gérard Leclerc: "Como a teoria abolia e conservava a cultura primitiva, da mesma forma a passagem para a vida civilizada abole e conserva o quanto existe de positivo na vida primitiva: esta última é abolida pela destruição por parte da colonização de todas as práticas aberrantes, conservadas na medida em que a sociedade colonizadora passou pelos mesmos estágios que a sociedade colonizada e se apresenta como a sua verdade, constituindo-a como um de seus momentos superados. A colonização contemporânea é a prática de uma sociedade que contém, que é a verdade da história". (G. Leclerc, Anthropologie et Colonialisme. Essai sur I'histoire de l'africanisme, Paris, Fayard, 1972, p. 35). O panorama da literatura dos séculos XVI e XVII sobre o "selvagem" é mais variado e complexo, e o quadro histórico de referência é diferente, é aquele do colonialismo mercantilista europeu - précolonialista, segundo a interpretação de Lenin -, mas me parece que, em geral, a relação do Ocidente com o outro se servia da mediação da razão natural universal, que, caso a caso, incluía ou excluía os "selvagens". 


\section{Marco Vanzulli}

63 L. Althusser, Lire Le Capitale cit., vol. I, p. 77.

64 L Althusser, La Reproduction des Rapports de Production cit., p. 48.

65 L. Althusser - E. Balibar, Lire le Capital, cit., vol. II, pp. 50-51.

66 Cf. E. de Martino, Magia e Civilità, Milano, Garzanti, 1995, pp. 8-9.

67 Cf. G. Leclerc, Anthropologie et Colonialisme cit.

68 L. Althusser, Sur Lévi-Strauss cit., p. 420.

69 Cf. a questão do "critério da autenticidade" in C. Lévi-Strauss, "Place de l'Anthropologie dans les Sciences Sociales et Problèmes Posés par son Enseignement", in Anthropologie Structurale cit., pp. 400-403; e, naturalmente, La Pensée Sauvage.

70 C. Lévi-Strauss, "Place de l'Anthropologie dans les Sciences Sociales et Problèmes Posés par son Enseignement" cit., p. 397 [N.E.: tr. bras. cit., p. 404].

71 E. de Martino, Magia e Civiltà cit., p. 9. Sabemos bem, diga-se de passagem, que a "globalização", ainda que uniformize e aproxime, e reduza praticamente a nada, em alguns casos, os fatores do espaço e do tempo, não elimina a diferença específica entre o plano universal e o particular, o global e o local, se tanto evidencia de um modo novo. É sobretudo o capital que é global e livre dos vínculos territoriais, enquanto o plano local é freqüentemente sujeito a lógicas globais que ele não controla e das quais sofre as conseqüências.

NT Aproximadamente vivência e empatia.

72 Cf. E. de Martino, "Fenomenologia Religiosa e Storicismo Assoluto", in /d., Storia e Metastoria. / fondamenti di uma teoria de/ sacro, a cargo de M. Massenzio, Lecce, Argo, 1995, pp. 47-74.

73 L. Althusser, Sur Lévi-Strauss cit., p. 421.

74 Idem, p. 423.

75 Idem, p. 424.

76 Idem, pp. 424-425. "Um dos resultados mais espetaculares da sua teoria é de ser completamente incapaz de dar conta do fato de que as estruturas de parentesco nas sociedades primitivas não estão em toda parte e nem são sempre as mesmas, mas apresentam variações consideráveis. Tais variações são para ele apenas variações de um modo de combinação puramente formal, o que é apenas tautológico, mas que não explica nada. Quando você oferece um modo de combinação que permite uma infinidade de formas possíveis na sua matriz combinatória, a pergunta pertinente não é se esse real (essa estrutura de parentesco observável) seja desde o início, antecipadamente, incluído como possível entre as variações da combinatória (porque, isso, é tautológico, consiste em constatar que o real era possíve/), mas a pergunta pertinente é a seguinte: por que esse possível, e não um outro, é que ocorreu, é portanto real?" (idem, p. 425).

77 L. Althusser, "Contradiction et Surdétermination", in Pour Marx, p. 111.

78 Cf. D. Ribeiro, O Processo Civilizatório. Etapas da evolução sociocultural. São Paulo, Companhia das Letras, 1999, p. 88.

79 Balibar nota analogamente que à regularidade do ciclo do capital não corresponde a sucessão das figuras do político, cf. E. Balibar, L'Europa, I'America, la Guerra, tr. it. a cargo de S. Bonura, Roma, Manifestolibri, 2003, p. 69.

80 L. Althusser, L'Objet du Capital cit., vol. I, pp. 128-133.

81 Idem, vol.Il, p. 57.

82 L. Althusser, La Reproduction des Rapports de Production cit., p. 43.

83 Idem, p. 50. 
Althusser sobre Lévi-Strauss e sobre o Estatuto da Antropologia Cultural

perspectiva que decide o primado das relações de produção sobre as forças produtivas, ou melhor, a unidade das relações e das forças produtivas sob a primazia das relações de produção, Althusser coloca "em seu devido lugar, a economia política, as forças produtivas, a técnica ,etc." (idem, p. 62) Cf. também L. Althusser, La Reproduction des Rapports de Production cit., pp. 44-45, 51-58 e 243-252. O primado das forças produtivas sobre as relações de produção, que estariam entre elas como o conteúdo na forma, é próprio do Marx "hegeliano" dos Manuscritos Econômico-Filosóficos, d'A Ideologia Alemã e da Introdução à Crítica da Economia Política, enquanto em O Capital se encontraria a afirmação do primado das relações de produção. Na história do marxismo, se situariam na primeira corrente os teóricos da II Internacional, Bernstein e Kautsky, também Stalin, na segunda, Lenin e Mao, cujo sucesso revolucionário sera incompreensível de outra forma, cf, id., pp. 248-249.

85 Idem, pp. 47-48, 54 e 251.

86 C. Lévi-Strauss, "Place de l'Anthropologie dans les Sciences Sociales et Problèmes Posés par son Enseignement" cit., p. 388.

87 Cf. K. Marx, // Capitale, a cargo de D. Cantimori, Roma, Editori Riuniti, 1993, vol. I, p. 414.

88 Cf. L. Althusser, La Reprodustion des Rapports de Production cit, pp. 47-48.

NT A tradução da expressão latina corresponderia, aproximadamente, em português à a parte construtiva. 